\title{
Studying Youth Transitions Through \\ a Social Network: First Impressions
}

\author{
Véronique Eicher, Mouna Bakouri, Christian Staerklé, \\ Marlene Carvalhosa Barbosa, and Alain Clémence
}

\section{The Study of Youth Transitions}

Young adulthood is a period during which many important life transitions in the professional and educational domain occur, for example choosing an educational track, passing selection procedures into higher education, selecting an occupation, finding a job (e.g., Fleeson and Cantor 1995; Pimentel 1996). It has been shown that successful or unsuccessful regulation of these transitions influences future transitional choices and actions (Heckhausen and Schulz 1995; Nurmi 1993). The transitional choices, as well as the way young individuals deal with developmental tasks and challenges, are influenced by various factors, ranging from the available choices and perceived opportunities to specific regulation strategies of failures to differential levels of vulnerability (e.g., Salmela-Aro 2009). The present study focuses on the relationship between different types of vulnerability (internal and external), regulation strategies, and life transitions in young adults aged 1530 years. We specifically investigate how young people manage professional and educational transitions, in particular transitions from school to higher education and from school or vocational training to first employment. We assume these transitions to be influenced by different levels of internal and external vulnerability, as well as by different types of regulation strategies. External vulnerability refers to factual aspects like material (e.g., low income) or categorical (e.g., member of

\author{
V. Eicher $(\square)$ \\ Social Work, Zurich University of Applied Sciences, Zurich, Switzerland \\ NCCR LIVES, IP 9, Chavannes-près-Renens, Switzerland \\ e-mail: eicr@zhaw.ch \\ M. Bakouri • C. Staerklé • M.C. Barbosa • A. Clémence \\ NCCR LIVES, IP 9, Chavannes-près-Renens, Switzerland \\ Institute of Psychology, University of Lausanne, Lausanne, Switzerland
}

(C) The Author(s) 2016

M. Oris et al. (eds.), Surveying Human Vulnerabilities across the Life Course,

Life Course Research and Social Policies 3, DOI 10.1007/978-3-319-24157-9_9 
lower status group) vulnerability that increase the likelihood of negative events and decrease the number of opportunities (e.g., Eccles 1994; Pascoe and Richman 2009). Internal vulnerability, in turn, refers to the internalization of factual vulnerabilities affecting people's sense of agency, efficacy and motivation that can be expressed as psychological (e.g., perceived lack of control) or relational (e.g., perceived lack of social support) forms of vulnerability (Eccles and Wigfield 2002; Salmela-Aro 2009). Different types of regulation strategies include the attribution of success and goal selection and adjustment (e.g., Brandstädter 2009; Heckhausen 1999) (i.e., cognitive-motivational strategies), in-group identification and endorsement of collective norms (e.g., Turner et al. 1994) (i.e., group-based strategies), as well as ideological beliefs and political activism (e.g., Staerklé 2009) (i.e., politicalinstitutional strategies).

The online network to be described in this chapter was intended to provide the opportunity to investigate two research questions understood as instances of group-based regulation of developmental tasks and life transitions (i.e., exchange with others, identification with significant others). In order to be as close to participants' everyday life and their preferred communication tools as possible, we designed an online social network, which would allow participants to communicate with each other on topics of their own choosing. In the following, we first give the theoretical background of the two research questions before presenting the methodology with which we planned to investigate these group-based regulatory strategies.

\subsection{Research Questions Related to the Online Social Network}

In line with developmental research demonstrating the importance of co-regulation in dealing with life course transitions (Salmela-Aro 2009), we expected exchange of experiences with individuals facing similar challenges to be a central regulatory strategy. Sharing the struggles and fears, but also successes of life course transitions may indeed be beneficial for both sides. 'Talking' about one's experience may help to better understand and cope with it. 'Hearing' about other people's experiences can procure a sense of sharedness, knowing that other people face similar difficulties.

Prior research has analysed whether online social networks are associated with social capital and exchange with friends in general. For instance, it has been shown that people who use Facebook often have more bridging capital (i.e., weak ties with dissimilar others that may provide information but no emotional support; Putnam 2000) independent of their level of self-esteem or life satisfaction, while less intensive Facebook users with lower self-esteem or satisfaction indicate less bridging capital (Ellison et al. 2007). In an extension of this study, Steinfield et al. (2008) showed that Facebook use led to more bridging social capital 1 year later, rather than the other way around. 
Bonding capital, in contrast, refers to social connectedness with similar others, typically in-group members. This "feeling of belonging to a social group" (Köbler et al. 2010, p. 2) has been studied in association with Facebook use where it was shown that the more people post information on social networks, the more connected they feel to others (Köbler et al. 2010). When asked why they are on Facebook, users indicated mostly social motives like connecting with others and meeting likeminded people (only a small group of people indicated using Facebook mainly for playing games). Additionally, they liked to tell others about what happened to them and to look at what others were doing (Joinson 2008). Online social networks are thus used as a facilitator for social relationships. Introverted individuals and those with lower self-esteem for example indicate using the network mainly to build new relationships and considering online communication as more effective for developing in-depth communication than face-to-face interactions (Valkenburg and Peter 2007; Valkenburg et al. 2005).

Beyond the beneficial aspect of enlarging the social network and sharing experiences, Valenzuela et al. (2009) investigated the association between Facebook use and different well-being outcomes. They showed that, although these effects were not large, Facebook use was positively associated with social trust, life satisfaction, political participation, and civic engagement. These findings suggest that use of social networks does not lead to social isolation - as is often proclaimed by "cyberpessimists" (Valenzuela et al. 2009, p. 893) - but can even have beneficial effects on real-life interactions. Overall, these studies point to the usefulness of online networks to strengthen and widen the social network and the perceived importance of social interactions. We thus assumed that participants may want to share their transition experiences with others and extend their network to similar others. As a first research question, we are therefore interested in the role of exchange of experiences with other individuals facing similar transitions in life course regulation and its implications for well-being.

A second major research question concerns the role of identification with significant others as a way to cope with difficult transitional demands. Socialpsychological theories concerned with the psychological manifestations of group membership (i.e., Social Identity Theory, Self-Categorization Theory) analyse how individuals shift between personal and social identities as a function of their memberships in social groups (e.g., Tajfel 1978; Turner et al. 1987). Identifying oneself with a group can provide social support such that difficult or negative experiences may be better regulated when one feels like a member of a group (e.g., Outten et al. 2009).

One of the first social psychological studies of computer-mediated communication (CMC) analysed communication patterns in computer-mediated vs. face-to-face settings (Kiesler et al. 1984). The authors showed that participants interacted more equally (there were fewer dominant individuals) in CMC and suggested that, because dominance and group information are less visible over computer, computermediated interactions may be more equal and less influenced by existing group differences. This quite optimistic view of CMC - of breaking down social barriers and norms - has been questioned by the Social Identity model of Deindividuation 
Effects (SIDE; Reicher et al. 1995). Here, anonymity and deindividuation make the social identity more salient and thus provoke strong reliance on the norms of the in-group and a rejection of the out-group rather than a breakdown of social barriers (Postmes et al. 1998). Thus, it appears that the anonymity of CMC, and thus of social networks, does not eliminate existing group boundaries. Rather, it leads to an emphasis of social identity that transforms an interpersonal interaction into an intergroup interaction, thus re-establishing the group boundaries found in real life. Such a view is supported by a study on the formation of group norms in CMC carried out over several months in the context of a computerized statistics course (Postmes et al. 2006). In this study, groups of students differed from each other with regard to length of messages, time frame of messages or the number of references to oneself, for instance. Analysing the messages over time, the authors found that they tended to get more prototypical for each group over time, but only for communication among group members: When participants sent messages to an out-group, their messages were not prototypical for their group. All of these studies point to the salience of group identities in CMC and suggest similar group effects in online social networks. We therefore examine the role of group identification in the context of online social networks and analyse whether this identification helps individuals to cope with the demands of life transitions.

\subsection{Outline of the Study Methodology}

The present study on youth transitions follows a longitudinal mixed-methods design over a period of at least 4 years during which participants are contacted once a year. All participants first complete a questionnaire, assessing a broad range of different types of vulnerability and regulation strategies as well as transitional projects and life course goals. In this questionnaire, they are asked for their email address and a username for their registration to the online social network. For all participants who indicate an email address a user account is created in the online social network of the study. Besides the analysis of the role of communicational exchange and social identification in life course regulation, the social network is also used as a way to stay in contact with the participants for the duration of the study. Finally, a small subgroup of participants is selected for in-depth interviews about their use of specific regulation strategies.

We use these different methods of data collection to answer different types of research questions, but also to adapt our methodology as much as possible to commonly-used communication channels of participants. They are young adults aged 15-30 years who are in a more or less vulnerable position regarding their professional trajectory (i.e., some already have stable employment, while others have trouble even finding an apprenticeship place) and their level of education (ranging from compulsory schooling to university diploma). The network may thus help to encourage participation by young adults who may not be used to completing questionnaires and writing texts. 


\section{Online Social Networks}

Online social networks have become increasingly popular among young adults as a method of connecting with peers. The first online social networks were created in the 1990s and became a mass phenomenon during the 2000s with the creation of MySpace, Facebook, Google+, etc. Today, the most widely used online social network, Facebook, has more than 900 million users (ranging from $5 \%$ of the total population in Africa to $45 \%$ of the total population in North America), half of which log in every day (Socialbakers 2012). In Switzerland, where our study was conducted, approximately $40 \%$ of the population has a Facebook account, a percentage that rises to more than $75 \%$ among young adults (16-34 years old) (Socialbakers 2012). These statistics suggest at the very least a widespread use of computer-mediated communications tools among young adults.

\subsection{Reasons for Using an Online Social Network in a Study on Youth Transitions}

The assumption that a majority of young adults in Switzerland uses online social networks was one of the key reasons why we decided to use this method. In contrast to standardized questionnaires, an online network would give participants the opportunity to express themselves via a media they are supposedly comfortable with and used to. And as we are particularly interested in more vulnerable populations, this option seemed even more important: Instead of frightening off (or boring) participants with standardized questions, we wanted to give them the possibility to participate in the study with the method they often use to communicate with others.

A second major reason to use an online social network was its flexibility as a method of data collection. Participants can use the network whenever they want for as long as they want. This permits a completely flexible time schedule both for participants and for researchers. Participants could 'talk' about their experiences as soon as they happen instead of several weeks or months later (when researchers happen to collect data). This immediacy might minimize recall effects, which are often particularly strong for emotional experiences (Thomas and Diener 1990). The same way that participants can choose freely when to use the network, researchers can use the network flexibly to ask questions and stimulate discussions at different time points. The flexibility of networks is not limited to the temporal aspect, but also extends to the format of the data collection. Researchers can post closed and open-ended questions, invite participants for one-item-polls, invite discussions on specific topics and so on. The network thus offers a more flexible way to study different topics than questionnaires and interviews typically allow.

A third advantage of the online social network is the ease of contacting the participants. Our participants are young adults who experience many life transitions, like starting a new school or job, moving out of the parental home or moving in 
with a partner or friends. This period in life is thus marked by many changes, which can make it more difficult to stay in contact with participants. By using participants' email address to create an account on an online social network, participants could be contacted independently of employment changes or moving house. If participants change their email address, they can adapt this in their user account, making the continuity of the account potentially independent of changes in people's lives.

Another reason that led to the decision of the creation of an online social network was to increase the fidelity of participants over the course of the study. Through an online social network we hoped to be able to stay in contact with them, so they would not have forgotten about the study by the time they were next contacted. Additionally, we wanted to increase identification with our study through direct interaction with participants, a strategy also intended to decrease attrition rates.

\subsection{Reasons for Creating a New Online Social Network}

In order to build a strong study identity for our study, we wanted to create a new online social network for which we were able to decide the layout and the functions and connect it with a public website for the study. The new network would be closely linked to our study and by using the network, participants would also identify with the study itself, thus ensuring continuous participation.

The second major reason for creating a new network was to have a network that is exclusive to the participants in our study. All participants enter the network without previous and outside contacts and can focus solely on other participants of the study. In existing networks, people are already connected with other people and often have already developed a specific behavioural pattern on how to use the network. By creating a new network, we would be able to give all participants the same 'starting point' and could also analyse relevant behaviours of co-regulation that would have been difficult to study in an existing network (e.g., newly formed connections between individuals, creation of groups around specific topics).

A final reason for not relying on an existing network relates to data privacy. If we had integrated the study within an existing network, it would not have been possible to guarantee participants the privacy of their data, as it would be owned by the specific network. By creating our own network, we are able to ensure that participants' data is not used for commercial purposes and is solely used for research purposes within the research group.

\section{The Online Social Network "Projet Expériences"}

In this section, we present the online social network created for the purposes of the present study, named "Projet Expériences". First, we describe the concrete decisions and steps we took in the creation of the network. Then, we give an overview over 
some of the functions of the network and indicate how they relate to our research questions. In a third subsection, we show first results based on 365 participants. Finally, we conclude with the difficulties faced in the creation and maintenance of the network.

\subsection{Building the Network: Steps, Choices, and Difficulties}

Various functional goals determined the planning and the construction of the network. We wanted to be able to post closed and open-ended questions and short polls (i.e., flexibility of data collection), contact participants easily through a website and newsletters (i.e., ease of access to participants) and control access to the network (data privacy). Access control was also intended to link the network closely to the study and thus strengthen identification with it. Additionally, to study our research questions, we needed to create a platform, where participants could post texts and media contents (e.g., pictures, videos, music) to everyone or just the research team, as well as interact with other users online through friendship connections and exchange private and public messages. Finally, we wanted the network to be similar to existing networks so that participants would feel comfortable and experienced in using it.

We started exploring the different possibilities for creating a social networking platform, inspired by the features of the most popular existing ones (Facebook and Twitter). Giving the current success of online communities, many Content Management Systems (CMS) are freely available on the internet. CMS are applications providing tools for creating, editing, and publishing web content for non-expert users (among the most used CMSs are Drupal, Joomla, and Wordpress). The main difficulty was to compare and choose between the different options, as there are many different applications and plug-ins (software components that add specific functions) and it thus takes time to explore the advantages, compatibility and performance of each one. Together with the IT team of the university of Lausanne, we decided to use Wordpress, as the IT centre already had experience with the musthave plug-ins for this CMS and was ready to collaborate in the construction of the network.

\subsection{Building Our Online Social Network Using Wordpress}

Wordpress is a free and open-source software allowing the creation of blogs and websites. With the multitude of plug-ins available, Wordpress is also able to transform a website into a real network. We made sure that all the features we wanted were possible with this CMS and checked with the IT team that we had the necessary system requirements to use it. Before installing WordPress, we had to define our domain name and register it on a domain registration website 
(e.g., GoDaddy). The domain name should reflect the content of the website, be easy to remember and of course be available. As our project was interested in young people's life experiences, we chose "ProjetExperiences.ch" (i.e., project experiences).

As we wanted to include social networking features in addition to simple blogs, we installed Buddypress, a powerful plug-in for Wordpress that enables participants to interact with each other and transforms Wordpress into a social network platform. Before we customized our website and social network, we chose a theme that handles the layout of the site and its content and determines the features available on the platform. We chose "Buddypress social" as it allows us to display different pages to users who are signed in versus others who are not. This way, we were able to make the description and results of our project public to all visitors, while restraining the social network part (e.g., profiles and activities of participants) to logged users. This theme allows additional interaction features like displaying the most commented posts and the most popular groups, improving the interactive experience of the network. The only disadvantage of this theme is that it is not free (around $\$ 100$ per year). After installing the theme, we created the different pages of our public website, which is visible to everyone without registration. On this public website, we describe our project, present the research team and give regular updates on the results of the project. We also present the social network and shortly describe its main functions and uses. On this public website, we also suggest a calendar with regional events that could be of interest to our participants. Finally, we offer them "Useful links", a list of relevant websites (associative, informative, pedagogical or preventive) that may be useful for education, hobbies or health. After this public, and more classic, part of the platform, we customized the network using Buddypress plug-ins.

\subsubsection{Functions (and Related Plug-Ins)}

Buddypress is an elaborate plug-in with many features that can be individually activated. We outline the different functions and describe the features of Buddypress required for each function.

Participants can update their profile using a variety of categories, like favourite films and books, and they can also give a brief description of themselves. The profile can give interesting information on how the participants define themselves and if they identify with specific groups (e.g., describing themselves as an apprentice or employee at a specific company). This function is possible with the feature "Extended Profiles".

The users can make friend connections by asking other users to be their friends. These connections are especially important for our research question on group identification as we can investigate if people make connections solely within their group (e.g., employees at a company) or if they try to enlarge their network by connecting with participants from other groups. This function is enabled by the feature "Friends". 
The users can post texts, links, pictures or videos they want to share with other members of the network and their activities are then displayed on the network for other members to see. This function is central to our research as it allows participants to express themselves on their day-to-day-life, but also on specific experiences. Additionally, they can choose to comment on posts of other participants, which is interesting in the context of shared experiences: Do participants comment by sharing similar experiences, offer advice, give feedback, or do not respond at all? The feature "Activity stream" allows the display of recent activities of each member, while an additional plug-in "Buddypress Activity Plus" allows sharing links, pictures, and videos. In addition to posting public texts, participants can send personal messages to other users directly, which only they can see (like emails). This function is possible with the feature "Private messaging".

Finally, participants can create and join groups based on specific topics that may interest them. This function is also central for our research as participants can write or discuss about topics that may be of specific concern to them at that time (e.g., their apprenticeship, their boss, their relationships). We are interested to see if people will discuss about their experiences regarding specific topics and if so, how this discussion will develop: Will people actively encourage each other or give advice or will they passively tell their own experiences while not engaging in a discussion with others. Additionally, it will be interesting to see if the language used in such groups (e.g., positive vs. negative "atmosphere", abbreviations, longer vs. shorter texts) will be different from group to group (similarly to the emergence of norms in the statistics course by Postmes et al. 2006). Next to these public groups, participants can also create private groups, which are only visible to the participant and the research team. Here, participants can talk about private experiences or use it as a diary to document their everyday life and events. This final function is enabled through the feature "Groups".

These plug-ins and features are integrated in the Buddypress package and are mostly designed to enrich the interpersonal and intergroup interactions, which was one of our priorities. To facilitate the management of our network we installed the following additional plug-ins, tested them and checked their compatibility with our BuddyPress theme: "Add New Users" (facilitates the addition of new users and attribution of different roles, e.g., subscriber for participants, administrator for research team), "Contact Form 7" (allows the creation of contact forms so participants and people interested on our project can easily contact us), "WP-polls" (enables the creation of quick polls on specific topics), "BP Redirect to profile for Buddypress" (redirects users to their profile and activity-page when they log in), and "Wysija Newsletters" (allows the design and creation of newsletters and makes it possible to import and manage our list of participants). Finally, we included "Connection attempts limit" to increase the security of our network: With this plugin, we prevent individuals or a robot from making unlimited login attempts, making the network more secure against attacks from outsiders. 


\subsubsection{Network Preparation and Maintenance}

Before registering the first users on our network, we created several groups on topics which we thought might be relevant to participants and would be interesting for us to collect data (e.g., my apprenticeship, my boss, my worries, my projects, feeling lonely). We wanted participants to join these groups, talk about their experiences in these different domains and discuss them with each other. We were interested to see how participants would talk about their experiences, how they would interpret them, but also how other users would react (e.g., by sharing their own experiences or offering their advice). Next to these research-relevant topics, we also created several groups around leisure-oriented topics to motivate participants to join the groups and discussions (e.g., music, sports, news, festivals, vacations). These groups are not primarily the focus of data collection, but were intended to give participants the possibility to exchange on less sensitive topics and to strengthen their fidelity to the network and the study.

Once the network was in use, we sent out newsletters to inform participants about new results of the study on the website and to announce the creation of new groups. We thereby wanted to remind participants of the network and the study and hoped to motivate them to $\log$ in by asking specific questions. Finally, we organised raffles (e.g., tickets for the movie theatre) to further motivate our participants to use the network.

With respect to our role as researchers on the network, all of the members of the research team had a user account with their first name and the mention "research team" in parentheses (e.g., Mouna (research team)). As such, we were readily identifiable by the participants as members of the research team. We updated our profile and sometimes posted comments in groups to stimulate the discussion. We could participate in discussions, but did not want to explicitly moderate the discussions between participants.

\subsection{Some Results Regarding the Use of the Network}

This section presents some preliminary results of the use of the network. The results are based on participants recruited from two institutions: The "Centre for Professional Formation and Orientation" (CPFO) and the "Municipality of Lausanne" (MOL). The CPFO is a centre for young adults who have difficulties finding an apprenticeship place or who do not know yet what type of apprenticeship they would like to do. Participants from this institution are thus particularly vulnerable regarding their professional trajectory. The MOL, in contrast, was chosen to get a comparison group of apprentices, as well as young employees, who are well integrated into the labour market. We were thus able to recruit participants at different stages of their professional development. 


\subsubsection{Participants and Procedure}

Participants from the CPFO were either pre-apprentices or apprentices, and those from the MOL either apprentices or young employees aged 16-30. These four groups of participants differed with regard to their professional situation. The employees from the MOL were in stable employment with little job insecurity. In contrast to the employees, the apprentices from the MOL may not be employed by the MOL afterwards, but their apprenticeship at this institution is likely to give them good prospects for their job search after the apprenticeship. The apprentices from the CPFO were unable to find an apprenticeship within a company and were thus less integrated in the job market than their counterparts from the MOL. Finally, the pre-apprentices from the CPFO had usually not yet chosen their specific professional track yet or had trouble finding an apprenticeship. These four groups thus differ with respect to their present professional situation, but also in their prospects for finding a stable employment in the future.

At the CPFO, members of the research team personally presented the study with a short description of its goals and the different methods of participation to the pre-apprentices and apprentices during one of their courses. The website and network was also briefly shown to participants, along with some of its functions. All of the pre-apprentices and apprentices who attended the presentation completed the questionnaire, but the rate of course absenteeism was high (51.7\% for preapprentices, $31.9 \%$ for apprentices).

At the MOL, participants were contacted with a letter describing the study and indicating the website of the study for further information, as well as a questionnaire with a return envelope. $28.9 \%$ of the apprentices and $28.7 \%$ of the employees completed the questionnaire. Table 1 indicates the socio-demographic characteristics of the sample of people who completed the first questionnaire.

\subsubsection{Measures}

The questionnaire included questions on regulation strategies and different types of vulnerability, as well as activities of young adults. Only the measures used in this chapter will be presented here.

Table 1 Means, standard deviations and percentages of socio-demographic variables of the sample that completed the first questionnaire

\begin{tabular}{l|l|l|l|l|l}
\hline & \multicolumn{2}{|l|}{ CPFO } & MOL & \multirow{2}{*}{} \\
\cline { 2 - 6 } & Pre-apprentices & Apprentices & Apprentices & Employees & Total \\
\hline Age: M (SD) & $16.68(0.85)$ & $19.35(1.83)$ & $19.07(2.91)$ & $26.42(2.34)$ & $22.24(4.61)$ \\
\hline Men: \% & 62.1 & 60.8 & 63.6 & 47.4 & 55.1 \\
\hline Swiss: \% & 43.9 & 53.2 & 78.2 & 89.0 & 72.7 \\
\hline N & 58 & 79 & 55 & 173 & 365 \\
\hline
\end{tabular}


Discrimination was assessed with one item, which was adapted from the European Social Survey: "Are you member of a group, which you believe is treated less well than other groups in Switzerland?" Answer options were yes (1) or no (0).

Financial worries were assessed with two items from the LIVES Daily Stress Inventory (Morselli et al. 2014). Participants reported to what degree they were worried about not having enough money to cover their living expenses (e.g., paying rent and bills) or needing financial aid (e.g., unemployment benefits, social aid). The items had to be rated on a scale from 1 (it does not worry me at all) to 4 (it worries me a lot).

Relational worries were assessed with two items from the LIVES Daily Stress Inventory (Morselli et al. 2014). Participants indicated to what extent they were worried about being alone or of having conflicts with family members on the same 4-point-scale as before.

Self-esteem was assessed with five items from the Rosenberg (1965) Self-Esteem scale, which had to be rated on a 6-point scale of 1 (not at all) to 6 (absolutely). One example item was "On the whole, I am satisfied with myself".

Lack of control was assessed with one item from the Perceived Stress Scale (Cohen et al. 1983), which had to be rated on a 6-point scale of 1 (not at all) to 6 (absolutely): "I feel that I am unable to control the important things in my life".

Internet use and computer access. In addition to these psychological questions, participants were asked about their use of internet and computer resources. They were asked what they did on the Internet and could select multiple answers: (1) read and write emails, (2) participate on an online social network, and (3) surf on websites. Additionally, they were asked how often they use the Internet on the following 5-point scale: 0 (never or almost never), 1 (several times per month), 2 (several times per week), 3 (everyday), and 4 (several times per day). Finally, they were asked whether they possessed or had easy access to a computer and/or a smartphone.

\subsubsection{Who Has an Online Account?}

In a first questionnaire, we asked all participants to indicate their name and contact details (i.e., postal and email address) to be able to contact them again. Additionally, we asked them to provide a username for the online social network. Of the 365 participants completing the questionnaire, 280 participants $(76.7 \%)$ indicated a valid email address so that we were able to create an account for each of them. In order to determine who is more or less likely to provide a valid email address, we ran a logistic regression analysis including socio-demographic variables in a first step and computer and internet use in a second step. In a final step we included the different types of vulnerability discussed in the introduction.

As our study focuses on vulnerability, it is important to know whether our methodology is adapted to our participants or if - on the contrary - the most vulnerable participants decide not to participate in the social network. We ran these analyses with the entire sample ( $N=365$ participants). 
Table 2 Means, standard deviations and percentages of computer use and vulnerabilities of the whole sample $(N=365)$

\begin{tabular}{|c|c|c|c|c|c|}
\hline & \multicolumn{2}{|c|}{ CPFO } & \multicolumn{2}{|l|}{ MOL } & \multirow[b]{2}{*}{ Total } \\
\hline & Pre-apprentices & Apprentices & Apprentices & Employees & \\
\hline \multicolumn{6}{|l|}{ Access to } \\
\hline Computer $(\%)$ & 93.1 & 87.2 & 96.4 & 98.3 & 94.8 \\
\hline Smartphone (\%) & 41.4 & 50.0 & 76.4 & 75.6 & 64.7 \\
\hline \multicolumn{6}{|l|}{ Internet use } \\
\hline Emails $(\%)$ & 57.9 & 57.7 & 87.3 & 91.3 & 78.2 \\
\hline Social network (\%) & 80.7 & 80.8 & 89.1 & 75.6 & 79.6 \\
\hline Surfing $(\%)$ & 73.7 & 76.9 & 90.7 & 94.8 & 87.0 \\
\hline Frequency $(0-4)$ & $2.85(1.06)$ & $2.96(0.97)$ & $3.41(0.78)$ & $3.47(0.69)$ & $3.25(0.87)$ \\
\hline \multicolumn{6}{|l|}{ Vulnerability } \\
\hline \multicolumn{6}{|l|}{ External } \\
\hline Discrimination $(\%)$ & 26.8 & 11.3 & 18.2 & 30.8 & 24.3 \\
\hline Financial worries $(1-4)$ & $2.24(0.88)$ & $2.45(0.79)$ & $2.34(0.82)$ & $2.14(0.81)$ & $2.25(0.82)$ \\
\hline \multicolumn{6}{|l|}{ Internal } \\
\hline Relational worries (1-4) & $2.11(0.98)$ & $2.08(0.93)$ & $2.35(0.89)$ & $2.15(0.90)$ & $2.16(0.92)$ \\
\hline Self-esteem (1-6) & $4.63(0.99)$ & $4.75(0.93)$ & $4.43(0.79)$ & $4.57(0.71)$ & $4.60(0.82)$ \\
\hline Lack of control (1-6) & $2.61(1.42)$ & $2.63(1.47)$ & $2.27(1.25)$ & $2.30(1.29)$ & $2.41(1.35)$ \\
\hline
\end{tabular}

Table 2 presents the means and standard deviations and percentages of computer and Internet use, as well as of the different vulnerability types. Table 3 shows the results of the logistic regression analysis on the indication of a valid email address.

The large majority of the participants owns a computer or has easy access to one, with employees from the MOL being more likely to have one than apprentices from the CPFO $\left(X^{2}(3)=13.88, p=0.003\right)$. Participants from the MOL were more likely to own a smartphone than participants in the $\mathrm{CPFO}\left(X^{2}(3)=33.40, p<0.001\right)$.

Regarding Internet use, the participants from the MOL read their emails and surfed on the Internet more than participants from the CPFO $\left(X^{2}(3)=52.90\right.$, $p<0.001$ and $\left.X^{2}(3)=25.75, p<0.001\right)$. They also spent more time on the Internet (several times a day) than participants from CPFO (once a day, $F(3,359)=12.30$, $p<0.001)$. Apprentices in the CPFO were less likely to report having experienced discrimination than employees from the MOL $\left(X^{2}(3)=11.83, p=0.008\right)$. This finding is surprising to the extent that the percentage of Non-Swiss is much higher in the CPFO than in the MOL. It therefore suggests that discrimination may be related to different groups within the different samples: Although most employees from the MOL are Swiss, they may be discriminated against based on gender, class, political orientation, and so on. There are no significant differences in the remaining vulnerabilities between the participants. All groups have relatively low levels of financial and relational (i.e., interpersonal) worries, as well as lack of control, while self-esteem is relatively high. 
Table 3 Logistic regression analysis on the indication of a valid email address (unstandardized coefficients, standard errors and odds ratios) $(N=365)$

\begin{tabular}{|c|c|c|c|c|}
\hline DV: indication of valid email address & B & S.E. & Odds ratio & Sig. \\
\hline \multicolumn{5}{|l|}{ Socio-demographic } \\
\hline Age & 0.12 & 0.073 & 1.12 & 0.112 \\
\hline Gender: Men & 0.11 & 0.315 & 1.12 & 0.720 \\
\hline Nationality: Swiss & 0.05 & 0.364 & 1.05 & 0.885 \\
\hline Group status & & & & 0.038 \\
\hline Group: Pre-apprentices CPFO & 1.34 & 0.518 & 3.84 & 0.009 \\
\hline Group: Apprentices MOL & 0.89 & 0.534 & 2.45 & 0.094 \\
\hline Group: Employees MOL & -0.45 & 0.655 & 0.64 & 0.490 \\
\hline \multicolumn{5}{|l|}{ Access to } \\
\hline Computer & 0.69 & 0.683 & 1.99 & 0.313 \\
\hline Smartphone & 0.36 & 0.333 & 1.44 & 0.279 \\
\hline \multicolumn{5}{|l|}{ Internet use } \\
\hline Emails & 0.81 & 0.361 & 2.25 & 0.025 \\
\hline Social network & -0.16 & 0.380 & 0.85 & 0.674 \\
\hline Surfing & 0.86 & 0.432 & 2.36 & 0.047 \\
\hline Frequency & 0.22 & 0.192 & 1.25 & 0.251 \\
\hline \multicolumn{5}{|l|}{ Vulnerability } \\
\hline \multicolumn{5}{|l|}{ External } \\
\hline Discrimination & 0.51 & 0.417 & 1.67 & 0.222 \\
\hline Financial worries & -0.35 & 0.204 & 0.70 & 0.083 \\
\hline \multicolumn{5}{|l|}{ Internal } \\
\hline Relational worries & 0.51 & 0.198 & 1.67 & 0.010 \\
\hline Self-esteem & -0.42 & 0.227 & 0.66 & 0.068 \\
\hline Lack of control & -0.02 & 0.129 & 0.98 & 0.876 \\
\hline
\end{tabular}

Reference group for group status are apprentices from CPFO

Pre-apprentices from the CPFO (74.1\%) and apprentices from the MOL (85.5\%) were more likely to indicate a valid email address than apprentices from the CPFO $(58.2 \%)$. People who write emails and surf the Internet regularly were more likely to indicate an email address $(81.7 \%$ and $80.3 \%$ respectively) than those who do not (60.8\% and $57.4 \%$ respectively). Surprisingly, participating in an online social network had no impact on indicating a valid email address: Online social network users were neither more nor less likely to indicate an address $(78.2 \%)$ than others $(73.0 \%)$. Of the different types of vulnerability, financial worries were associated with lower likelihood of providing a valid email address, while relational worries predicted the indication of an email address positively. Additionally, people with high self-esteem were less likely to indicate a valid email address. These results suggest that people with internal vulnerabilities rather than material ones were especially interested in joining the online social network. Age, gender, and nationality did not have significant effects. 
Table 4 Sample sizes and percentages of participants logging in and/or doing something on the network

\begin{tabular}{|c|c|c|c|c|c|c|c|c|c|c|}
\hline & \multicolumn{4}{|c|}{$\mathrm{CPFO}$} & \multicolumn{4}{|c|}{ MOL } & \multirow{2}{*}{\multicolumn{2}{|c|}{ Total }} \\
\hline & \multicolumn{2}{|c|}{ Pre-apprentices } & \multicolumn{2}{|c|}{ Apprentices } & \multicolumn{2}{|c|}{ Apprentices } & \multicolumn{2}{|c|}{ Employees } & & \\
\hline & $\mathrm{N}$ & $\%$ & $\mathrm{~N}$ & $\%$ & $\mathrm{~N}$ & $\%$ & $\mathrm{~N}$ & $\%$ & $\mathrm{~N}$ & $\%$ \\
\hline Account & 43 & 74.1 & 46 & 58.2 & 47 & 85.5 & 144 & 83.2 & 280 & 76.7 \\
\hline Log in: no & 42 & 97.7 & 39 & 84.8 & 32 & 68.1 & 103 & 71.5 & 216 & 77.1 \\
\hline Log in: yes & 1 & 2.3 & 7 & 15.2 & 15 & 31.9 & 41 & 28.5 & 64 & 22.9 \\
\hline Activity: no & 0 & 0.0 & 1 & 14.3 & 11 & 73.3 & 34 & 82.9 & 46 & 71.9 \\
\hline Activity: yes & 1 & 100.0 & 6 & 85.7 & 4 & 26.7 & 7 & 17.1 & 18 & 28.1 \\
\hline
\end{tabular}

\subsubsection{Who Uses the Online Account?}

As mentioned above, an account was created for the 280 participants who provided a valid email address. We now turn to see who has been going online and/or been active on the network. Table 4 shows the sample size and percentages of participants logging in to the network and/or doing something on it.

The results show a dire picture of participation: Only about a quarter of the participants actually logged in at least once into the network. This percentage was low for pre-apprentices $(2.3 \%)$ and apprentices from the CPFO (15.2\%), while reaching almost a third for the participants from the MOL. This first step of actually logging into the network once is thus clearly a barrier for most participants.

The loss of participants at this stage may be due to two causes: (1) participants receive the username and are not interested to log into the network or (2) participants do not receive the username because the email address is not correct or they do not read their emails regularly.

Although we cannot determine the cause of the loss, the second explanation is supported by some indices. As we saw before, participants from the CPFO are much less likely than participants from the MOL to even log in even once, and they are also much less likely to regularly read their emails as indicated in Table 2. Additionally, when we sent an email to the winners of the first raffle, not all of the winners contacted us to collect their tickets, indicating that they may not have read the email in the first place (we asked them to verify their postal address so that we could send the tickets).

Interestingly, while the participants from the CPFO were much less likely to actually $\log$ in than participants from the MOL, once they did log in, almost all of them did something on the network. The opposite was true for participants from the MOL who were more likely to have a look around without doing anything. To investigate who is more likely to actually go online (independently of doing something or not), we ran a logistic regression analysis on those who had logged in at least once (as opposed to those who never logged in) including the same predictors as before. The only significant predictor was group status: Apprentices from the MOL $(O . R .=12.13, p=0.024)$ and employees from the 
MOL $(O . R .=8.25, p=0.084)$ were more likely to go online than those from the CPFO. None of the vulnerability types predicted more or less use of the network.

\subsection{Difficulties}

These findings show without ambiguity that participants are very reluctant to log in to the network to begin with, and when they do so, that it is highly likely that they will leave without leaving any trace. For the first log-in to the network, for example, more than two-thirds of the participants are lost. The difficulty of this participant loss is that we cannot determine whether people do not receive the log-in details and therefore do not $\log$ in, or whether they do receive them, but are not motivated to $\log$ in. Of those who do log in, only a small percentage of participants actively does something (those from the CPFO were somewhat more active than those from the MOL). These findings underscore the necessity to motivate participants actively and interactively, at least in the beginning, to join and to be active on the network. We tried to do this with raffles for network participants and asking questions for specific topic groups, but these measures can only be effective if participants actually read their emails.

Most of the activity on the network happens in areas less oriented towards research: Participants mostly updated their profile with a picture and their favourite music or sports, but without any self-description or discussion that could have been used for research purposes. Some joined groups without posting something and none actually joined the research-related groups at all. The fact that most activity happened in non-research-related domains like uploading pictures and joining "fun" groups does not, however, mean that the network cannot be used for research purposes. Participants may want to get used to the network and meet fellow users doing fun activities before posting personal comments on topics, which may be more sensitive (e.g., worries, projects).

Finally, the creation and maintenance of the network requires a considerable amount of time as well as technical skill and knowledge. Although the CMS in general, and Wordpress and Buddypress specifically, are developed for non-experts, users still need to invest time and effort to make such a network work. The utility of all the features and plug-ins, as well as their compatibility with each other, need to be tested and re-tested. Before going online, we did a pilot study with around 50 colleagues to see if the network and all the functions would work as they should. Now that the network is online, we still need to update the software and its plugins regularly to ensure the effective functioning of the website. Time is also needed for the regular update of the network and website. The calendar of regional events needs to be updated every few weeks and we try to create new groups around current topics to keep participants interested. 


\section{Conclusion and Future Directions}

There can only be one conclusion with respect to the use of newly created social networks for research purposes, and it is rather disappointing: It is exceedingly difficult to attract participants to $\log$ in and then to use the network, not to mention to bring them to contribute to the network on a regular basis and to interact with others in a scientifically exploitable way. With hindsight, it may well be that as researchers we were overly optimistic not to say blinded by the scientific possibilities of a network and at the same time not sensitive enough to real-life constraints of young adults. Or more simply, the expectations of researchers were fundamentally incompatible with the everyday motivations of participants. We have the impression we did everything we could in order to set up an attractive and functional network only to observe that it did not make much of a difference. This outcome just seems to show that successful implementations of "high-tech" solutions to study social science problems require a tremendous amount of preparation, organisation and communication, and thus funding.

But not everything is lost. There are several possibilities that could make the network more attractive to young adults. First, with the necessary funding, it would be possible to financially compensate active participation in the network according to clear guidelines, thereby potentially creating a self-sustaining dynamic within the network.

Second, the network could be opened to the public at large so that the participants of our study could also communicate with their friends or other persons who do not participate in the study. This would make the network even more similar to the usual social networks with the advantage, however, that we would maintain data privacy. Opening up the network could also lead to a transformation of the website into a network on life transitions in general where individuals could share their experiences and life events. Websites, which follow a similar procedure are www.experienceproject.com and www.microaggressions.com for instance, which are regularly visited by people all over the world to "talk" about their everyday experiences.

Third, we might focus the network on topics that are most relevant to our participants. For instance, we could focus on topics like finding an apprenticeship position for pre-apprentices, thus creating a platform that has also practical instead of only scientific goals. Such a network would maybe also send a message to participants that the research team is sensitive to issues of concern for participants. We are presently evaluating these different options aimed at reinventing the network. The future will show whether these changes result in a different user behaviour among young participants, thus making it possible to address our original research questions. 
Open Access This chapter is licensed under the terms of the Creative Commons AttributionNonCommercial 2.5 International License (http://creativecommons.org/licenses/by-nc/2.5/), which permits any noncommercial use, sharing, adaptation, distribution and reproduction in any medium or format, as long as you give appropriate credit to the original author(s) and the source, provide a link to the Creative Commons license and indicate if changes were made.

The images or other third party material in this chapter are included in the chapter's Creative Commons license, unless indicated otherwise in a credit line to the material. If material is not included in the chapter's Creative Commons license and your intended use is not permitted by statutory regulation or exceeds the permitted use, you will need to obtain permission directly from the copyright holder.

\section{References}

Brandtstädter, J. (2009). Goal pursuit and goal adjustment: Self-regulation and intentional selfdevelopment in changing developmental contexts. Advances in Life Course Research, 14, 52-62.

Cohen, S., Kamarck, T., \& Mermelstein, R. (1983). A global measure of perceived stress. Journal of Health and Social Behavior, 24, 385-39.

Eccles, J. S. (1994). Understanding women's educational and occupational choices. Psychology of Women Quarterly, 18, 585-609.

Eccles, J. S., \& Wigfield, A. (2002). Motivational beliefs, values, and goals. Annual Review of Psychology, 53, 109-132.

Ellison, N. B., Steinfield, C., \& Lampe, C. (2007). The benefits of Facebook "friends:" Social capital and college students' use of online social network sites. Journal of Computer-Mediated Communication, 12, 1143-1168.

Fleeson, W., \& Cantor, N. (1995). Goal relevance and the affective experience of daily life: Ruling out situational explanations. Motivation and Emotion, 19, 25-57.

Heckhausen, J. (1999). Developmental regulation in adulthood. Age-normative and sociostructural constraints as adaptative challenges. Cambridge: Cambridge University Press.

Heckhausen, J., \& Schulz, R. (1995). A life-span theory of control. Psychological Review, 102, 284-304.

Joinson, A. N. (2008). Looking at, looking up or keeping up with people? Motives and use of facebook. Florence: Online Social Networks.

Kiesler, S., Siegel, J., \& McGuire, T. W. (1984). Social psychological aspects of computermediated communication. American Psychologist, 39, 1123-1134.

Köbler, F., Riedl, C., Vetter, C., Leimeister, J. M., Krcmar, H. (2010). Social connectedness on facebook-an explorative study on status message usage. Proceedings of 16th Americas Conference on Information Systems. Lima.

Morselli, D., et al. (2014). LIVES Daily Stress Inventory. Manuscript in preparation.

Nurmi, J.-E. (1993). Adolescent development in an age-graded context: The role of personal beliefs, goals and strategies in the tackling of developmental tasks and standards. International Journal of Behavioral Development, 16, 169-189.

Outten, H. R., Schmitt, M. T., Garcia, D. M., \& Branscombe, N. R. (2009). Coping options: Missing links between minority group identification and psychological well-being. Applied Psychology: An International Review, 58, 146-170.

Pascoe, E. A., \& Smart Richman, L. (2009). Perceived discrimination and health: A meta-analytic review. Psychological Bulletin, 135, 531-554. 
Pimentel, E. E. (1996). Effects of adolescent achievement and family goals on the early adult transition. In J. T. Mortimer \& M. D. Finch (Eds.), Adolescents work and family: An intergenerational developmental analyses (pp. 191-220). Thousands Oaks: Sage.

Postmes, T., Spears, R., \& Lea, M. (1998). Breaching or building social boundaries? SIDE-effects of computer-mediated communication. Communication Research, 25, 689-715.

Postmes, T., Spears, R., \& Lea, M. (2006). The formation of group norms in computer-mediated communication. Human Communication Research, 26, 341-371.

Putnam, R. D. (2000). Bowling alone: The collapse and revival of American community. New York: Simon \& Schuster.

Reicher, S. D., Spears, R., \& Postmes, T. (1995). A social identity model of deindividuation phenomena. European Review of Social Psychology, 6, 161-198.

Rosenberg, M. (1965). Society and the adolescent self-image. Princeton: Princeton University Press.

Salmela-Aro, K. (2009). Personal goals and well-being during critical life transitions: The four C's-Channelling, choice, co-agency and compensation. Advances in Life Course Research, 14, 63-73.

Socialbakers. (2012). Switzerland facebook statistics. Retrieved from: http://www.socialbakers. com/facebook-statistics/switzerland

Staerklé, C. (2009). Policy attitudes, ideological values and social representations. Social and Personality Psychology Compass, 3, 1096-1112.

Steinfield, C., Ellison, N. B., \& Lampe, C. (2008). Social capital, self-esteem, and use of online social network sites: A longitudinal analysis. Journal of Applied Developmental Psychology, $29,434-445$.

Tajfel, H. (1978). The social psychology of minorities. London: Minority Rights Group.

Thomas, D. L., \& Diener, E. (1990). Memory accuracy in the recall of emotions. Journal of Personality and Social Psychology, 59, 291-297.

Turner, J. C., Hogg, M. A., Oakes, P. J., Reicher, S. D., \& Wetherell, M. S. (1987). Rediscovering the social group: A self-categorization theory. Oxford: Blackwell.

Turner, J. C., Oakes, P. J., Haslam, S. A., \& McGarty, C. (1994). Self and collective: Cognition and social context. Personality and Social Psychology Bulletin, 20, 454-454.

Valenzuela, S., Park, N., \& Kee, K. F. (2009). Is there social capital in a social network site? Facebook use and college students' life satisfaction, trust, and participation. Journal of Computer-Mediated Communication, 14, 875-901.

Valkenburg, P. M., \& Peter, J. (2007). Preadolescents' and adolescents' online communication and their closeness to friends. Developmental Psychology, 43, 267-277.

Valkenburg, P. M., Schouten, A. P., \& Peter, J. (2005). Adolescents' identity experiments on the internet. New Media and Society, 7, 383-402. 